\section{BMJ Open}

Ophthalmology

\title{
Effectiveness and safety of azithromycin $1.5 \%$ eye drops for mass treatment of active trachoma in a highly endemic district in Cameroon
}

Assumpta Lucienne Bella, ${ }^{1}$ Ellen Einterz, ${ }^{2}$ Pierre Huguet, ${ }^{3}$ Philippe Bensaid, ${ }^{4}$ Abdou Amza, ${ }^{5}$ Didier Renault (i) 6,7

To cite: Bella AL, Einterz E, Huguet $\mathrm{P}$, et al. Effectiveness and safety of azithromycin $1.5 \%$ eye drops for mass treatment of active trachoma in a highly endemic district in Cameroon. BMJ Open Ophthalmology 2020;5:e000531. doi:10.1136/ bmjophth-2020-000531

Received 29 May 2020 Revised 16 October 2020 Accepted 18 0ctober 2020

Check for updates

(C) Author(s) (or their employer(s)) 2020. Re-use permitted under CC BY-NC. No commercial re-use. See rights and permissions. Published by BMJ.

${ }^{1}$ Health Ministry, National Programme for Blindness Control/MoPH, Yaoundé, Cameroon

2Department of Ophthalmology, Kolofata District Hospital, Kolofata, Cameroon

${ }^{3}$ Organisation pour la Prévention de la Cécité, Paris, France

${ }^{4}$ Ophthalmo Sans Frontières, Luçon, France

${ }^{5}$ Faculté des Sciences de la Santé, Abdou Moumouni University, Niamey, Niger ${ }^{6}$ Thea Open Innovation, Laboratoires Théa, ClermontFerrand, Auvergne-Rhône-Alpes, France

${ }^{7}$ Fondation Théa, ClermontFerrand, France

Correspondence to Dr Didier Renault; didier. renault@theaopeninnovation. com

\section{ABSTRACT}

Objective To evaluate the effectiveness and safety of azithromycin $1.5 \%$ eye drops under field conditions to reduce active trachoma in a highly endemic district in Cameroon. This is a follow-up of an initial report published in 2010.

Methods and analysis Three annual campaigns were performed in 2008, 2009 and 2010 to treat the population ( 120000 individuals) of the Kolofata Health District with topical azithromycin 1.5\% (one drop in each eye, morning and evening for three consecutive days). The effectiveness of this intervention against active trachoma was assessed in children aged 1-9 years in cross-sectional studies prior to each mass treatment using a systematic sampling procedure (in 2008, 2009 and 2010) and then 1 year (2011) and 3 years (2013) after the last intervention among the villages with previously high active trachoma prevalence or never tested.

Results The prevalence of trachomatous inflammationfollicular (TF) dropped from $24.0 \%$ (95\% Cl 20.7 to 27.5$)$ before treatment to $2.8 \%(95 \% \mathrm{Cl} 2.2$ to 3.7$) 1$ year after completion of the 3 year campaign. Trachomatous inflammation-intense was present in only $4(0.2 \%)$ children 1 year after the third round of treatment. Three years after the last campaign, the surveillance survey among the most prevalent villages and villages never tested before showed a prevalence of $5.2 \%(95 \% \mathrm{Cl} 3.6$ to 7.2) of active trachoma. Tolerance was excellent, with no report of treatment interruption, serious ocular or systemic adverse events.

Conclusion Annual mass treatment with azithromycin eye drops was shown to be effective in reducing TF to a level $\leq 5 \%$ one year after a 3 -round annual mass treatment in an endemic region at the district level.

\section{INTRODUCTION}

Trachoma is a chronic infective condition of the eye caused by the microorganism Chlamydia trachomatis. It is the leading infectious cause of blindness worldwide and was previously estimated to be responsible for visual impairment in 1.6 million individuals, of which 0.4 million were irreversibly blind. ${ }^{1}$ The disease begins in early childhood. It is seen mostly in children in association with

\section{Key messages}

What is already known about this subject?

Elimination of trachoma is a public health issue in endemic regions.

- Annual mass treatment should be repeated until a prevalence of trachomatous inflammation-follicu$\operatorname{lar}(\mathrm{TF})<5 \%$ in the impact survey.

$>$ A surveillance survey at least 2 years after mass treatment cessation is necessary to validate the elimination of trachoma.

\section{What are the new findings?}

Azithromycin $1.5 \%$ eye drops was effective to reduce the TF prevalence in a high-endemic district in Cameroon.

The effectiveness was sustained 1 year and 3 years after the last treatment round.

\section{How might these results change the focus of research or clinical practice?}

- Azithromycin $1.5 \%$ eye drops could be proposed as an alternative to oral azithromycin or tetracycline ointment in endemic regions especially for treating young children particularly those under 6 months of age and not eligible for oral azithromycin or people unable or reluctant to take oral azithromycin.

red, sticky eyes, with symptoms of itchy, painful eyes. In the WHO simplified system, the two defined signs of active trachoma are trachomatous inflammation-follicular (TF, defined as the presence of five or more follicles measuring at least $0.5 \mathrm{~mm}$ in diameter in the upper tarsal conjunctiva) and trachomatous inflammation-intense (TI, defined as pronounced inflammatory thickening of the tarsal conjunctiva that obscures more than half of the normal tarsal vessels).$^{2}$ Repeated inflammation from cycles of infection and reinfection causes entropion, trichiasis, corneal abrasion and corneal opacity which may lead to blindness. ${ }^{34}$ The disease is associated with poor sanitation and inadequate water access. ${ }^{5}$ Transmission occurs mainly by 
close contact at home, both directly (via contaminated hands) and indirectly (via clothing, other contaminated materials or the bodies of eye-seeking flies). ${ }^{34}$

In 1993, the WHO endorsed a multifaceted strategy (SAFE) for the elimination of trachoma as a public health problem. ${ }^{6}$ In 1996, WHO launched the WHO Alliance for the Global Elimination of Trachoma by the year 2020 (GET2020), a partnership which supports country implementation of the SAFE strategy and the strengthening of national capacity through epidemiological assessment, monitoring, surveillance, project evaluation and resource mobilisation. ${ }^{7}$ The 'SAFE strategy' comprises Surgery for trachomatous trichiasis; Antibiotics to clear ocular C. trachomatis infection; Facial cleanliness and Environmental improvement to reduce transmission (particularly access to water and sanitation). The A, F and $\mathrm{E}$ should be delivered to entire endemic districts (usually populations of 100000-250000 inhabitants). The threshold for annual mass treatment with antibiotics was set at $10 \%$ prevalence. If TF prevalence was $10 \%$ or more, the whole district should be mass treated with antibiotics. If it was between $5 \%$ and $10 \%$, then treatment should only be implemented at the community level. ${ }^{8}$ The global recommendation was to conduct annual mass treatments for a minimum of 3 years. These treatments must not be stopped until the TF level among children aged 1-9 had fallen below $5 \%$. In the report of the 3rd Global Scientific Meeting on Trachoma, WHO recommended trachoma assessment at the subdistrict or village level when the TF prevalence fell below $10 \%$ in $1-9$ years old children. ${ }^{9}$ In more recent years, the recommendation has been taken as permission to treat all residents of districts in which the $\mathrm{TF}$ prevalence is $5 \%-9.9 \% .{ }^{10}$

Mass treatment campaigns for the prevention of blindness due to trachoma have been run using oral azithromycin, and numerous community-based trials have provided evidence that such treatment reduces the prevalence of active trachoma and ocular chlamydia infection. ${ }^{11}$ Using this strategy, several endemic countries have reported the elimination of trachoma as a public health problem during the last decade. ${ }^{12}$ Africa remains the most endemic region in the world, and it was recently estimated that more than 117 million people in the WHO African region ( $87 \%$ of all cases in the world) warranted treatment with the antibiotics, facial cleanliness and environmental improvement. In the Republic of Cameroon, the prevention of blindness and visual impairment represents one of the public health priorities of the Ministry of Public Health. ${ }^{13}$ In December 2006, a study assessing the prevalence of active and scarring trachoma in the Kolofata Health District (in Far North Cameroon) signalled the presence of endemic trachoma with significant blinding potential. ${ }^{13}{ }^{14}$ Subsequently, The National Blindness Control Programme decided to plan an elimination programme by implementing the WHO-SAFE strategy and performing mass treatment of the entire district population.
A randomised, controlled, double-masked, doubledummy study in children aged 1-10 years old with active trachoma previously showed that azithromycin $1.5 \%$ eye drops (one drop in each eye, morning and evening for three consecutive days) was as efficient as oral azithromycin to resolve active trachoma at 60 days. ${ }^{15}$ It was thus decided to use topical azithromycin $1.5 \%$ to reduce the prevalence of active trachoma in the Kolofata Health District. First results of the impact surveys showed reduction of active trachoma below $5 \% 1$ year after the second round of mass treatment with azithromycin eye drops. ${ }^{1617}$ Here, we additionally report the effectiveness and safety results 1 year and 3 years after completion of the 3-year mass campaign.

\section{METHODS}

\section{Mass treatment campaigns}

Three annual mass treatments of all people living in the Kolofata Health District were implemented in 2008, 2009 and 2010 by the Cameroon Health Authorities, in partnership with the non-governmental organisation Ophthalmo Sans Frontières (OSF) and Laboratoires Théa (Clermont-Ferrand, France).

An exhaustive door-to-door census of all residents of the District (about 112000 people) was conducted by 250 local, community-trained health workers, each assigned to a village or neighbourhood of 400-500 residents. The objective was to treat the entire population, including children less than 1 year old, with azithromycin $1.5 \%$ eye drops donated by Laboratoires Théa, as one drop in each eye, morning and evening for 3 consecutive days. The treatment administration was performed by the same community health workers under the supervision of an ophthalmic nurse during a 2-week period. A briefing was organised in Kolofata Hospital each evening where ophthalmic nurses reported the assessment of the mass treatment, including questionnaires intended to document any side effects or symptoms of the eye drops.

\section{Prevalence surveys}

The objective of this study was to assess the effectiveness of community-based treatment with 3 days of azithromycin eye drops in reducing the prevalence of active trachoma in children aged 1-9 years ( $\geq 1$ year and up to their 10th birthday). Five cross-sectional prevalence studies at 1-year intervals were planned to assess active trachoma in children aged 1-9 years in 2008 (prior to the first mass treatment), 2009 (prior the second mass treatment), 2010 (prior to the third and last mass treatment), 2011 (1 year after the last mass treatment) and 2013 (3years after the last mass treatment).

Prevalence surveys before mass treatment $(2008,2009$ and 2010) From the 2006 survey data, ${ }^{13}$ the internal cluster (ie, within village) correlation was estimated at 0.034 . Assuming a prevalence of about $5 \%$ at the end of the third year, it was necessary to include 40 villages with at least 60 evaluable children per village, that is, 2400 children, to get a $95 \%$ 
CI with a half-length of $1.5 \%$. Thus, 40 villages (or neighbourhoods) were selected systematically using probability proportional to size. Within the selected cluster (village or neighbourhood), all households were identified and numbered, and all their members were registered based on the local census listing. Then, an initial house was randomly selected. A sampling interval (randomly chosen before the beginning of the study) identified the following houses to be included in the sample. The sampling continued until it achieved selection of 60 children aged between 1 and 9 years of age who had lived for at least 6 months in the village on the day of the survey. If a family had left the community for over 6 months and the house was empty on the day of the survey, the house was replaced by the nearest one. In the case of an empty household or of a missing child among the randomly selected, the survey team had to repeat their visit three times to check for the presence of the selected child. If after the third visit, the selected child could not be met, he or she was considered absent and not replaced.

\section{Impact survey and surveillance survey after treatment cessation (2011 and 2013)}

An impact survey was performed 1 year after the third mass treatment campaign (2011) and the surveillance survey was conducted 3 years after the last campaign (2013). Although 40 villages were randomly selected in 2008, 2009, 2010, it was shown that active trachoma was more prevalent in some villages or families. For the 2011 and 2013 surveys, since there was no clear recommendation on how to perform the surveillance survey, it was deemed acceptable to focus on communities or villages with a higher risk of trachoma, as stated in the 3rd WHO Global Scientific Meeting (2010) and the WHO Strategic and Technical Advisory Group in 2018. ${ }^{918}$ Consequently, we used the two-stage sampling within each of two parallel sampling approaches in the same district: the previously high prevalence villages in the previous surveys, and the previously non-sampled villages. This was done based on the lot quality assessment sampling, a method previously proposed by Myatt et al for a rapid assessment of prevalence of active trachoma. ${ }^{19} 20$ The other sample was composed of children from households never sampled, thus taking into account possible residual infection among villages never tested before.

\section{Clinical assessments of active trachoma}

TF and TI were separately assessed using the WHO simplified grading system. ${ }^{21}$ Active trachoma was assessed based on TF prevalence alone in line with the WHO recommendations. ${ }^{8}$ The prevalence of TI was considered as a secondary criterion.

All children enrolled in the study were examined by a senior ophthalmic nurse and/or an ophthalmologist. The examiner everted the upper eyelid and inspected the conjunctiva by means of a $2.5 \times$ magnifying glass and a torch held by an assistant in charge of recording the data. Before examining the next child, the examiner verified that the assistant had filled out the study sheet in accordance with study protocol guidelines. After a 4-day training session, prior to the study, each examiner was tested on 50 children with and without trachoma. Following evaluation, the inter-grader variation for TF and TI was almost perfect comparing each examiner to the reference grader (kappa scores between 0.81 and $1.00)$.

\section{Assessment of safety}

Drug-related serious adverse events were assessed and recorded each day during the treatment administration and 7 days after the last administration for all treated subjects (children and adults).

\section{Statistical methods}

The prevalence of active trachoma was estimated based on the presence of TF alone. Data were compiled and analysed using EPIINFO V.6 software (Center for Disease Control and Prevention, Atlanta, Georgia, USA). 95\% CI were estimated taking into account the composition of sample clusters. Prevalences at different time points were not compared with a statistical test because the methodology for village selection changed over time, and was specifically biassed in 2011 and 2013.

\section{RESULTS}

Mass treatment campaign using azithromycin $1.5 \%$ eye drops Mass treatment was performed for more than 100000 inhabitants of the Kolofata Health District in 40 communities, representing a coverage of about $90 \%$ each year (table 1).

\section{Prevalence surveys in children aged 1-9 years}

In all, 2517 children were evaluated in 2008 (year 0) before treatment, 2402 in 2009 (year 1), 2582 in 2010 (year 2), 1933 in 2011 (year 3) 1 year after the last mass treatment and 2484 in 2013 (year 5) 3years after the last mass treatment. Age and sex of children were similar each year (table 2).

\begin{tabular}{llll}
\hline Table 1 Mass treatment coverage & & & \\
\hline & Population & Treated population & Coverage rate (\%) \\
\hline First treatment round (2008) & 115274 & 111340 & 96.6 \\
Second treatment round (2009) & 118616 & 105802 & 89.2 \\
Third treatment round (2010) & 122056 & 111171 & 91.1 \\
\hline
\end{tabular}




\begin{tabular}{|c|c|c|c|c|c|}
\hline & 2008 & 2009 & 2010 & 2011 & 2013 \\
\hline Number of selected villages/clusters & 40 & 40 & 40 & 31 & 41 \\
\hline Number of subjects assessed & 2517 & 2402 & 2582 & 1933 & 2484 \\
\hline \multicolumn{6}{|l|}{ Age, years } \\
\hline Mean (SD) & $4.2(2.3)$ & $4.1(2.3)$ & $4.6(2.4)$ & $4.4(2.5)$ & $4.5(2.2)$ \\
\hline \multicolumn{6}{|l|}{ Sex } \\
\hline Female, n (\%) & $1232(48.9)$ & $1169(48.7)$ & $1266(49.0)$ & $977(50.6)$ & $1226(49.4)$ \\
\hline Male, n (\%) & $1285(51.1)$ & 1233 (51.3) & $1316(51.0)$ & $956(49.4)$ & $1258(50.6)$ \\
\hline
\end{tabular}

SD, Standard deviation.

\section{Prevalence before each mass treatment round}

In 2008, before the first mass treatment campaign, the prevalence of TF alone was estimated at $24.0 \%(95 \%$ CI 20.7 to 27.5$)$. This dropped significantly to $5.8 \%(95 \%$ CI 4.1 to 8.0 ) after the first mass treatment and to $3.1 \%$ (95\% CI 2.0 to 4.9) after the second round, achieving the elimination level of $<5 \%$. Regarding TI, the prevalence was significantly reduced from $7.5 \%$ (95\% CI 5.7 to 10.0 ) of examined children before the first treatment round to $0.0 \%$ (95\% CI 0.0 to 0.8 ) 1 year after second treatment round (table 3 ).

\section{Impact survey after three rounds of treatment}

The impact survey showed a TF prevalence of $2.8 \%(95 \%$ CI 2.2 to 3.7) and a TI prevalence of $0.2 \%$ (95\% CI 0.0 to 1.3) 1 year after the third (table 4 ).

\section{Surveillance survey after treatment cessation}

The surveillance survey showed a TF prevalence of $5.2 \%$ (95\% CI 3.6 to 7.2 ) and a TI prevalence of $1.0 \%$ (95\% CI 0.6 to 1.4$)$, 3 years after the last administration of treatment (table 4).

\section{Safety of azithromycin $1.5 \%$ mass treatment}

In this mass population study, more than 100000 subjects including the youngest children $(<1$ year old) were treated each year for 3 years. No ocular or systemic serious adverse event related the study drug was reported in adults and children, during the 3 days of treatment administration and the seven following days. No treatment interruption was required in adults or children. Local and transitory symptoms including blurred vision and burning sensation, following eye drop instillation) occurred in some subjects but were not systematically recorded.

\section{DISCUSSION}

In 2008, the District of Kolofata was highly endemic for trachoma, with $24.0 \%$ of $1-9$ years old children with TF and $7.5 \%$ with TI. The prevalence of active trachoma in this district justified the mass treatment of the entire population with 3 yearly rounds of azithromycin as part of the SAFE strategy. ${ }^{8}$ This study is the first to use topical azithromycin in mass treatment to reduce the prevalence of active forms of trachoma in an endemic population and included a surveillance survey 3 years after treatment mass cessation. After two annual rounds of mass treatment with topical azithromycin covering more than $90 \%$ of the entire population, an estimated TF prevalence of $3.1 \%$ was reached, and the WHO objective for elimination of active trachoma (prevalence $<5 \%$ ) was met. This was maintained 1 year after a third annual round, during which children were chosen among the most prevalent villages and among villages never tested. In parallel, the presence of TI was detected in less than $1 \%$ of subjects after the second and third annual mass treatments, which is encouraging since TI subjects are those most likely to develop cicatricial complications as the disease progresses. $^{22} 23$

This study confirms previous results of a randomised clinical trial demonstrating that topical azithromycin $1.5 \%$ eye drops were at least as effective as the standard treatment in reducing the prevalence of active trachoma below $5 \% .^{15}$

A major concern when implementing a programme for eliminating trachoma is still to determine when to stop antibiotic treatment and preventive interventions ${ }^{24} 25$ and to determine the potential rebound in prevalence of active trachoma after interventions are stopped. As recommended in the WHO guidelines, a surveillance

\begin{tabular}{lllll}
\hline \multicolumn{7}{l}{ Table 3} & Prevalence of active trachoma prior to each mass treatment round & \\
\hline & & $\mathbf{2 0 0 8}$ & $\mathbf{2 0 0 9}$ & $\mathbf{2 0 1 0}$ \\
& & $\mathbf{N}=\mathbf{2 5 1 7}$ & $\mathbf{N}=\mathbf{2 4 0 2}$ & $\mathbf{N}=\mathbf{2 5 8 2}$ \\
\hline TF & $\mathrm{n}, \%(95 \% \mathrm{Cl})$ & $603,24.0(20.7$ to 27.5$)$ & $140,5.8(4.1$ to 8.0$)$ & $81,3.1(2.0$ to 4.9$)$ \\
TI & $\mathrm{n}, \%(95 \% \mathrm{Cl})$ & $190,7.5(5.7$ to 10.0$)$ & $14,0.5(0.13$ to 1.6$)$ & $0,0(0.0$ to 0.8$)$ \\
\hline
\end{tabular}

TF, trachomatous inflammation-follicular; TI, trachomatous inflammation-intense. 


\begin{tabular}{|c|c|c|c|}
\hline & & $\begin{array}{l}2011 \\
N=1933\end{array}$ & $\begin{array}{l}2013 \\
\mathrm{~N}=2484\end{array}$ \\
\hline TF & $\mathrm{n}, \%(95 \% \mathrm{Cl})$ & $54,2.8$ (2.2 to 3.7 ) & $128,5.2$ (3.6 to 7.2 ) \\
\hline $\mathrm{TI}$ & n, \% (95\% Cl) & $4,0.2$ (0.0 to 1.3$)$ & $26,1.0$ (0.6 to 1.4$)$ \\
\hline
\end{tabular}

$\mathrm{TF}$, trachomatous inflammation-follicular; TI, trachomatous inflammation-intense.

survey should be conducted at least 2 years after the impact survey to show that elimination targets is maintained in 1-9years old children, as an indicator of trachoma elimination. ${ }^{26}$ Three to five years, or five to seven years of implementation of SAFE may be insufficient to achieve trachoma elimination as a public health problem in some endemic regions. Some severely affected districts in Ethiopia have been treated for a decade and have still not achieved the prevalence threshold of $5 \%$ for halting treatment. ${ }^{27}$ In our study, although active trachoma seemed to be eliminated after three annual rounds of treatment, it persisted in a few communities after treatment cessation. Three years after the last round of treatment, the surveillance survey using a two-stage sample procedure including the most prevalent villages and villages never tested before showed a TF prevalence of $5.2 \%$, just above the WHO prevalence determined as the threshold necessary for the complete elimination of trachoma as a public health problem. Although the effectiveness of the SAFE strategy using oral azithromycin distribution has been demonstrated in numerous endemic populations worldwide ${ }^{12}$ the effect of mass treatment at the village level is known to be heterogeneous. ${ }^{28}{ }^{29}$ In low-endemic countries such as Gambia, a single oral dose of mass antibiotic treatment was sufficient to control C. trachomatis infection when combined with environmental conditions, such as good water supply and sanitation, with no re-emergence 5 years after treatment cessation. ${ }^{30}$ However, in more endemic regions, complete trachoma elimination in all communities may be difficult to achieve. Lakew et al showed that although trachoma prevalence was lowered to an average of $2.6 \%$ after four biannual treatments, prevalence had returned to $25.2 \%$ 2years after the last treatment, indicating that if infection is not eliminated at the community level, it may return. ${ }^{29}$ In Mali, a 3-round mass treatment with oral azithromycin reduced the prevalence of active trachoma from $17 \%$ to less than $5 \%$, but 3 years later trachoma started to re-emerge. ${ }^{31}$

Thus, the risk of re-emergence of trachoma once antibiotic pressure is removed is currently a major concern. ${ }^{25}$ Factors affecting the success of a Mass Drug Administration programme have been recently identified using a mathematical model of disease transmission. ${ }^{32}$ This included antibiotic treatment-related factors, such as coverage, dosing and frequency of distribution, and resistance. Antibiotic mass treatment coverage is an important issue since untreated individuals may serve as a source of community reinfection. WHO considered that coverage of $80 \%$ is acceptable, and increasing coverage above $90 \%$ in children does not appear to confer additional benefit. ${ }^{33}{ }^{34}$ Nevertheless low coverage rates $(<60 \%)$ of oral azithromycin mass treatment was reported in some highly endemic districts in Ethiopia. ${ }^{35}$ This can be due to a low acceptability of the oral azithromycin in some regions, in particular because of the fear of adverse events, as suggested previously. ${ }^{36}$ Oral azithromycin is generally well tolerated during mass treatment distribution, ${ }^{25}$ and has been associated with reduced all-cause and infectious childhood mortality. ${ }^{37}$ Nevertheless, up to $10 \%$ of people may experience side effects, primarily gastrointestinal disorders (abdominal pain, nausea and diarrhoea) ${ }^{38}$ Adverse effects in the first annual mass treatment round have been considered as a 'great public health concern' in some endemic regions which may compromise acceptability and treatment coverage.$^{3536}$ Moreover, in endemic communities, some individuals may be suspicious of taking an oral medicine for an eye disease. By contrast, we confirmed that topical azithromycin $1.5 \%$ was safe even in the youngest children of less than 6 months, as previously reported in different studies. ${ }^{15} 39$ Thus, topical azithromycin may be more easily accepted and could be proposed as an alternative when oral azithromycin is refused or contra-indicated. We assume that this could improve the coverage in some districts or communities where the trachoma elimination or control is difficult.

A recent meta-analysis showed that absence of latrines, dirty faces of children, and no reported use of soap for washing may be other important factors associated with active trachoma among children. ${ }^{40}$ In the Kolofata District, re-emergence was shown in several villages with impaired access to water due to borehole pump dysfunction or dry wells during a part of the year. Re-emergence of active trachoma above $10 \%$ in 1-9years old children was also reported in several Kolofata District villages in which face washing among children was notably deficient. ${ }^{41}$ As in other endemic regions, while the $\mathrm{S}$ and $\mathrm{A}$ components have been widely implemented, evidence and specific targets are lacking for the $\mathrm{F}$ and $\mathrm{E}$ components, of which water, sanitation and hygiene are critical elements. ${ }^{5}$ The current recommendation for antibiotic mass treatment is to treat all the district community including infants of less than 6 months. It is known that the probability of being infected by $C$. trachomatis is strongly influenced by age. Children aged less than 1 year have the highest bacterial load, and thus should be treated. ${ }^{42}$ Oral azithromycin is not recommended in children under 6 months of age, and tetracycline ointment is typically used. In contrast, treatment with $1.5 \%$ azithromycin eye drops is possible since azithromycin $1.5 \%$ is well tolerated in infants from 1 day of age ${ }^{43}$ Two times per day administration for 3 days with topical azithromycin $1.5 \%$ is also more convenient than tetracycline ointment, which requires two times per day instillations for 6 weeks. ${ }^{44}$ Thus, topical azithromycin may be proposed in place of tetracycline ointment to treat infants of less than 6 months. 
Azithromycin $1.5 \%$ eye drops have other advantages compared with oral azithromycin. The possibility of inadequate and thus ineffective oral dose, when calculated on the height stick in children, may lead to insufficient dosing which may be an issue especially when the bacterial load is high. ${ }^{25}$ In addition, eye drops avoid the potential issue of reconstituting an oral solution in a remote area. The use of topical azithromycin should also substantially reduce the risk of bacterial resistance. By contrast, repeated oral azithromycin mass distribution may be detrimental if it results in the selection of macrolide-resistant pathogens, and there is epidemiological evidence suggesting that pharyngeal carriage of macrolide-resistant Streptococcus pneumoniae increases following repeated annual mass treatments with oral azithromycin for trachoma control, as recently reviewed by O'Brien $e t \mathrm{al}^{45}$

Oral azithromycin is generously donated through the International Trachoma Initiative for trachoma control programmes and topical azithromycin may be a promising alternative to oral azithromycin if treatment units are donated similarly, which was the case in the Kolofata Health District. In addition, beside the costs of the treatment units, a campaign to eliminate trachoma as a public health problem is probably more expensive initially when topical rather than oral azithromycin is used, since the former requires health resources over 3 days and the latter only 1 day. Further studies that take into account both short-term and long-term costs and benefits are necessary to determine the overall cost-effectiveness of topical versus systemic azithromycin mass treatment. To reduce costs in a campaign using topical medication, more community members could be trained to administer the final 2 days of drops; expanding community involvement might have the added benefit of increasing community commitment. Basic training of such community or family eye drop administrators could be done on site on the first day of administration: the health worker would train a member of each family or group of families and that person would administer drops on days 2 and 3 . The feasibility and reliability of such a strategy remain to be investigated. In our situation, the administration of topical azithromycin to more than 100000 inhabitants was successful and logistically and financially similar to other subsidised mass drug and vaccine administration activities held previously in the district.

The study has some limitations including the lack of a control group, meaning a comparison between topical and oral azithromycin mass treatment cannot be made directly. Other components of the SAFE strategy were also applied during the mass treatment campaign, including surgery of entropion-trichiasis, educational activities to promote individual (facial cleanliness) and collective hygiene, and environmental changes. During the mass treatment campaign, the Cameroon government installed borehole water pumps, while the OSF built some wells. However, it is not known to what extent these interventions helped in reducing trachoma prevalence. Persistence and transmission of trachoma is favoured where people live in poverty without safe water, sanitation and proper waste disposal, and the disease may return after antibiotic treatment if these conditions are not changed. ${ }^{541}$ Moreover, the clinical grading was based on clinical observations in accordance with the WHO simplified grading system. ${ }^{21}$ Specific biological tests using serological and PCR markers may be more reliable for testing ocular TF infection. ${ }^{46}$ Furthermore, by selecting one part of the sample from the most prevalent villages of the previous years and the other part from villages never surveyed before, the prevalence of active trachoma in the follow-up surveys (2011 and 2013) was no longer representative of the district level. Finally, standardisation for age as recommended by the recent WHO guidelines in $2018^{18}$ was not possible. Such analysis was not planned at time of data recording, and data for the available census performed in the Kolofata District at that time could not be retrieved.

In conclusion, mass treatment with azithromycin eye drops was shown to be effective to reduce TF to a level $\leq 5 \%$ one year after a 3-round annual mass treatment in an endemic region at the district level. Longitudinal studies in multiple environments using epidemiologically rigorous sampling techniques are needed to ensure that the risk of re-emergence of disease and infection is not more likely than with oral azithromycin. Annual mass treatment of active trachoma with azithromycin 1.5\% eye drops is feasible under field conditions, although the cost-effectiveness of topical azithromycin needs to be determined. In the meantime such topical azithromycin treatment could be proposed as an alternative treatment to tetracycline ointment or oral azithromycin (1) for treating young children of less than 6 months, (2) for treating others unable to take oral azithromycin, (3) for mass drug administration where the oral azithromycin donation programme is unavailable and (4) where the population mistrusts oral azithromycin given for an eye condition.

Acknowledgements This study benefited from the expertise of the WHO Prevention of Blindness and Deafness Unit. The Ministry of Public Health of Cameroon placed at our disposal the personnel required for the success of the study. The authors also wish to thank Kolofata's traditional chiefs and heads of households for their hospitality and participation, and Thierry Radeau for medical writing service.

Contributors AA was the local responsible ophthalmologist in charge of treatment administration and trachoma evaluation; ALB was the study coordinator; EE contributed to the planning and execution of the study; PH was responsible for statistical methodology and for reporting of study results; DR coordinated the medical writing activities; AA, ALB, PB, EE, PH and DR reviewed and approved the final manuscript.

Funding The prevalence surveys were financed by the NGO Ophthalmo Sans Frontières. Laboratoires Théa donated the azithromycin 1.5\% eye drops and funded medical writing activities.

Competing interests PH was previously employed at Laboratoires Thea and DR is currently employed at Thea Open Innovation and at Fondation Thea.

Patient and public involvement Patients and/or the public were not involved in the design, or conduct, or reporting, or dissemination plans of this research.

Patient consent for publication Not required. 
Ethics approval The study was conducted in compliance with the ethical principles of the Declaration of Helsinki regarding biomedical research on human subjects. The study treatment plan received authorisation from the Cameroon Ministry of Public Health in February 2008. The National Ethics Committee of Yaoundé approved the study (Approval 098/CNE/DNM/07 and 086/CNE/DNM/08) and the method of obtaining informed consent. Informed consent was systematically requested from parents of minors. For people who were illiterate, the information sheet and informed consent were read to them. If they agreed to participate, the participant or a legally acceptable representative signed by fingerprint and a literate witness signed on behalf of the participant. Participants or the public were not involved in the design, or conduct, or reporting, or dissemination plans of this research.

Provenance and peer review Not commissioned; externally peer reviewed.

Open access This is an open access article distributed in accordance with the Creative Commons Attribution Non Commercial (CC BY-NC 4.0) license, which permits others to distribute, remix, adapt, build upon this work non-commercially, and license their derivative works on different terms, provided the original work is properly cited, appropriate credit is given, any changes made indicated, and the use is non-commercial. See: http://creativecommons.org/licenses/by-nc/4.0/.

ORCID iD

Didier Renault http://orcid.org/0000-0002-7164-0342

\section{REFERENCES}

1 Flaxman SR, Bourne RRA, Resnikoff S, et al. Global causes of blindness and distance vision impairment 1990-2020: a systematic review and meta-analysis. Lancet Glob Health 2017;5:e1221-34.

2 Thylefors B, Dawson CR, Jones BR, et al. A simple system for the assessment of trachoma and its complications. Bull World Health Organ 1987;65:477-83.

3 Wright HR, Turner A, Taylor HR. Trachoma. Lancet 2008;371:1945-54.

4 Taylor HR, Burton MJ, Haddad D, et al. Trachoma. Lancet 2014;384:2142-52.

5 Stocks ME, Ogden S, Haddad D, et al. Effect of water, sanitation, and hygiene on the prevention of trachoma: a systematic review and meta-analysis. PLoS Med 2014;11:e1001605.

6 Turner V, Francis V. Achieving community support for trachoma control (WHO/PBL/93.36). Geneva: World Health Organization, 1993 https://apps.who.int/iris/handle/10665/59567

7 World Health Organization. Future approaches to trachoma control: report of a global scientific meeting (WHO/PBL/96.56). Geneva: World Health Organization, 1997. https://apps.who.int/iris/handle/ 10665/63413

8 Buchan JC, Kuper H, Zondervan M, et al. Trachoma control: a guide for programme managers. Geneva: World Health organization, 2006. https://www.who.int/trachoma/resources/9241546905/en/

9 WHO. Report of the 3rd global scientific meeting on trachoma. Baltimore, USA, 19-20 July 2010. WHO/PBD/2.10. Geneva, Switzerland: World Health organization, 2010. https://www.who.int/ blindness/publications/WORLDHEALTHORGANIZATIONGSMmtgrep ortFINALVERSION.pdf?ua=1

10 Kalua K, Chisambi A, Chinyanya D, et al. One round of azithromycin MDA adequate to interrupt transmission in districts with prevalence of trachomatous inflammation-follicular of 5.0-9.9\%: Evidence from Malawi. PLoS Negl Trop Dis 2018;12:e0006543.

11 Evans JR, Solomon AW. Antibiotics for trachoma. Cochrane Database Syst Rev 2011:CD001860.

12 World health organisation alliance for the global elimination of trachoma by 2020: progress report on elimination of trachoma, 2019. Wkly Epidemiol Rec 2020;95:349-60.

13 Noa Noatina B, Kagmeni G, Mengouo MN, et al. Prevalence of trachoma in the far North region of Cameroon: results of a survey in 27 health districts. PLoS Negl Trop Dis 2013;7:e2240.

14 Goldschmidt P, Einterz E, Bensaid S, et al. Le trachome Au Cameroun: résultats d'une enquête épidémiologique dans Le district de Kolofata dans La Province de l'Extrême-Nord. Available: http://www.opht-sans-frontieres.org/Resources/enqtrachome.pdf [Accessed 27 Apr 2020].

15 Cochereau I, Goldschmidt P, Goepogui A, et al. Efficacy and safety of short duration azithromycin eye drops versus azithromycin single oral dose for the treatment of trachoma in children: a randomised, controlled, double-masked clinical trial. $\mathrm{Br} J \mathrm{O}$ Opthalmol 2007; $91: 667-72$

16 Huguet $\mathrm{P}$, Bella L, Einterz EM, et al. Mass treatment of trachoma with azithromycin $1.5 \%$ eye drops in the Republic of Cameroon: feasibility, tolerance and effectiveness. $\mathrm{Br} J$ Ophthalmol 2010;94:157-60.

17 Amza A, Goldschmidt P, Einterz E, et al. Elimination of active trachoma after two topical mass treatments with azithromycin 1.5\% eye drops. PLoS Negl Trop Dis 2010;4:e895

18 World Health Organization Strategic and Technical Advisory Group on Neglected Tropical Diseases. Design parameters for populationbased trachoma prevalence surveys (WHO/HTM/NTD/PCT/2018.07). Geneva: World Health Organization, 2018. https://apps. who.int/iris/ handle/10665/275523

19 Myatt M, Limburg H, Minassian D, et al. Field trial of applicability of lot quality assurance sampling survey method for rapid assessment of prevalence of active trachoma. Bull World Health Organ 2003;81:877-85.

20 Myatt M, Mai NP, Quynh NQ, et al. Using lot quality-assurance sampling and area sampling to identify priority areas for trachoma control: Viet Nam. Bull World Health Organ 2005;83:756-63.

21 Negrel AD, Tayor HR, West S. World Health organization. prevention of blindness and deafness. guidelines for rapid assessment for blinding trachoma. WHO PBD GET 00.8. 2001. Available: https://www.who.int/blindness/TRA-ENGLISH.pdf [Accessed 27 Apr 2020].

22 West SK, Muñoz B, Mkocha H, et al. Progression of active trachoma to scarring in a cohort of Tanzanian children. Ophthalmic Epidemiol 2001;8:137-44.

23 Wolle MA, Muñoz BE, Mkocha $\mathrm{H}$, et al. Constant ocular infection with Chlamydia trachomatis predicts risk of scarring in children in Tanzania. Ophthalmology 2009;116:243-7.

24 Jimenez V, Gelderblom HC, Mann Flueckiger R, et al. Mass drug administration for trachoma: how long is not long enough? PLOS Negl Trop Dis 2015;9:e0003610.

25 Wolle MA, West SK. Ocular Chlamydia trachomatis infection: elimination with mass drug administration. Expert Rev Anti Infect Ther 2019;17:189-200.

26 World Health Organization. Report of the 4th global scientific meeting on trachoma. Geneva, Switzerland, 27-29 November 2018. WHO/CDS/NTD/PCT/2019.03. Available: https://apps.who.int/iris/ bitstream/handle/10665/325121/WHO-CDS-NTD-PCT-2019.03-eng. pdf?ua=1 [Accessed 01 Sep 2020]

27 Stewart AEP, Zerihun M, Gessese D, et al. Progress to eliminate trachoma as a public health problem in Amhara national regional state, Ethiopia: results of 152 population-based surveys. Am J Trop Med Hyg 2019;101:1286-95.

28 Burton MJ, Holland MJ, Makalo P, et al. Re-Emergence of Chlamydia trachomatis infection after mass antibiotic treatment of a trachomaendemic Gambian community: a longitudinal study. Lancet 2005;365:1321-8.

29 Lakew T, Alemayehu W, Melese M, et al. Importance of coverage and endemicity on the return of infectious trachoma after a single mass antibiotic distribution. PLoS Negl Trop Dis 2009;3:e507.

30 Burton MJ, Holland MJ, Makalo P, et al. Profound and sustained reduction in Chlamydia trachomatis in the Gambia: a five-year longitudinal study of trachoma endemic communities. PLoS Negl Trop Dis 2010;4:e835.

31 Bamani S, King JD, Dembele M, et al. Where do we go from here? Prevalence of trachoma three years after stopping mass distribution of antibiotics in the regions of Kayes and Koulikoro, Mali. PLoS Negl Trop Dis 2010;4:e734.

32 Lietman TM, Pinsent A, Liu F, et al. Models of trachoma transmission and their policy implications: from control to elimination. Clin Infect Dis 2018;66:S275-80.

33 West SK, Bailey $\mathrm{R}$, Munoz $\mathrm{B}$, et al. A randomized trial of two coverage targets for mass treatment with azithromycin for trachoma. PLoS Negl Trop Dis 2013;7:e2415. eCollection 201.

34 Amza A, Kadri B, Nassirou B, et al. Effectiveness of expanding annual mass azithromycin distribution treatment coverage for trachoma in niger: a cluster randomised trial. $\mathrm{Br} J$ Ophthalmo 2018;102:680-6.

35 Tilahun Z, Fenta TG. Coverage of azithromycin mass treatment for trachoma elimination in northwestern Ethiopia: a community based cross-sectional study. BMC Ophthalmol 2018;18:193.

36 Desmond N, Solomon AW, Massae PA, et al. Acceptability of azithromycin for the control of trachoma in northern Tanzania. Trans $R$ Soc Trop Med Hyg 2005;99:656-63.

37 Keenan JD, Ayele B, Gebre T, et al. Childhood mortality in a cohort treated with mass azithromycin for trachoma. Clin Infect Dis 2011;52:883-8

38 Astale T, Sata E, Zerihun M, et al. Self-Reported side effects following mass administration of azithromycin to eliminate trachoma in Amhara, Ethiopia: results from a region-wide population-based survey. Am J Trop Med Hyg 2019;100:696-9. 
39 Afghani T, Mansoor H, Nadeem M. Preventing long-term ocular complications of trachoma with topical azithromycin: a 3-year follow-up study. Asia Pac J Ophthalmol 2017;6:8-12.

40 Gebrie A, Alebel A, Zegeye A, et al. Prevalence and associated factors of active trachoma among children in Ethiopia: a systematic review and meta-analysis. BMC Infect Dis 2019;19:1073.

41 Goldschmidt P, Einterz E. The limits of medical interventions for the elimination of preventable blindness. Trop Med Health 2014;42:43-52.

$42 \mathrm{Hu}$ VH, Harding-Esch EM, Burton MJ, et al. Epidemiology and control of trachoma: systematic review. Trop Med Int Health 2010;15:673-91.
43 Bremond-Gignac D, Nezzar H, Bianchi PE, et al. Efficacy and safety of azithromycin $1.5 \%$ eye drops in paediatric population with purulent bacterial conjunctivitis. Br J Ophthalmol 2014;98:739-45.

44 Bowman RJ, Sillah A, Van Dehn C, et al. Operational comparison of single-dose azithromycin and topical tetracycline for trachoma. Invest Ophthalmol Vis Sci 2000;41:4074-9.

45 O'Brien KS, Emerson P, Hooper PJ, et al. Antimicrobial resistance following mass azithromycin distribution for trachoma: a systematic review. Lancet Infect Dis 2019;19:e14-25.

46 Senyonjo LG, Debrah O, Martin DL, et al. Serological and PCRbased markers of ocular Chlamydia trachomatis transmission in northern Ghana after elimination of trachoma as a public health problem. PLoS Negl Trop Dis 2018;12:e0007027. 